\title{
Process evaluation within pragmatic randomised controlled trials: what is it, why is it done, and can we find it?-a systematic review
}

\author{
Caroline French $^{1 *}$ D, Hilary Pinnock ${ }^{2}$, Gordon Forbes ${ }^{3}$, Imogen Skene $^{4}$ and Stephanie J. C. Taylor ${ }^{1}$
}

\begin{abstract}
Background: Process evaluations are increasingly conducted within pragmatic randomised controlled trials (RCTs) of health services interventions and provide vital information to enhance understanding of RCT findings. However, issues pertaining to process evaluation in this specific context have been little discussed. We aimed to describe the frequency, characteristics, labelling, value, practical conduct issues, and accessibility of published process evaluations within pragmatic RCTs in health services research.
\end{abstract}

Methods: We used a 2-phase systematic search process to (1) identify an index sample of journal articles reporting primary outcome results of pragmatic RCTs published in 2015 and then (2) identify all associated publications. We used an operational definition of process evaluation based on the Medical Research Council's process evaluation framework to identify both process evaluations reported separately and process data reported in the trial results papers. We extracted and analysed quantitative and qualitative data to answer review objectives.

Results: From an index sample of 31 pragmatic RCTs, we identified 17 separate process evaluation studies. These had varied characteristics and only three were labelled 'process evaluation'. Each of the 31 trial results papers also reported process data, with a median of five different process evaluation components per trial. Reported barriers and facilitators related to real-world collection of process data, recruitment of participants to process evaluations, and health services research regulations. We synthesised a wide range of reported benefits of process evaluations to interventions, trials, and wider knowledge. Visibility was often poor, with 13/17 process evaluations not mentioned in the trial results paper and 12/16 process evaluation journal articles not appearing in the trial registry.

Conclusions: In our sample of reviewed pragmatic RCTs, the meaning of the label 'process evaluation' appears uncertain, and the scope and significance of the term warrant further research and clarification. Although there were many ways in which the process evaluations added value, they often had poor visibility. Our findings suggest approaches that could enhance the planning and utility of process evaluations in the context of pragmatic RCTs.

Trial registration: Not applicable for PROSPERO registration

Keywords: Process evaluation, Pragmatic randomised controlled trials, Health services research

\footnotetext{
*Correspondence: c.french@qmul.ac.uk

${ }^{1}$ Institute of Population Health Sciences, Barts and the London School of

Medicine and Dentistry, Queen Mary University of London, 58 Turner Street, London $\mathrm{E} 12 \mathrm{AB}$, UK

Full list of author information is available at the end of the article
}

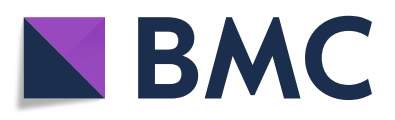

(- The Author(s). 2020 Open Access This article is licensed under a Creative Commons Attribution 4.0 International License, which permits use, sharing, adaptation, distribution and reproduction in any medium or format, as long as you give appropriate credit to the original author(s) and the source, provide a link to the Creative Commons licence, and indicate if changes were made. The images or other third party material in this article are included in the article's Creative Commons licence, unless indicated otherwise in a credit line to the material. If material is not included in the article's Creative Commons licence and your intended use is not permitted by statutory regulation or exceeds the permitted use, you will need to obtain permission directly from the copyright holder. To view a copy of this licence, visit http://creativecommons.org/licenses/by/4.0/. The Creative Commons Public Domain Dedication waiver (http://creativecommons.org/publicdomain/zero/1.0/) applies to the data made available in this article, unless otherwise stated in a credit line to the data. 


\section{Background}

There are increasing calls for process evaluations alongside outcome evaluations of complex healthcare interventions [1-3]. Defining features of 'complex interventions' include having multiple interacting components, addressing multiple outcomes, and targeting different levels of change within complex systems [4]. Process evaluations increase understanding of complex healthcare interventions by studying aspects of implementation, mechanisms of impact, and context [4]. They may thus shed light on the 'black box' of complex interventions and provide information to interpret outcome results and aid implementation into practice $[4,5]$. There has been similar increasing interest in the use of pragmatic randomised controlled trials (RCTs) to evaluate the outcomes of complex healthcare interventions $[1$, 6]. Pragmatic RCTs, in contrast to explanatory RCTs, aim to conduct 'real-world' evaluation of interventions, with findings that have enhanced generalisability to realworld clinical practice [6].

Masterson-Algar et al. [7] highlight the importance of tailoring process evaluation guidance to the context in which it will be used, and accordingly, this review aims to address gaps in knowledge about process evaluation conduct in the context of pragmatic RCTs of health services interventions. The UK Medical Research Council (MRC) published comprehensive guidance for designing and conducting process evaluations of complex interventions in 2014 [4], following earlier process evaluation frameworks by other authors [5, 8, 9]. However, apart from Grant et al.'s framework [5], these were developed primarily for public health research. Although being described as applicable to health services research, many of the examples in the MRC's guidance [4] are from a public health perspective. It is therefore useful to review process evaluation conduct in health services settings as these are likely to present some unique challenges. The few published systematic reviews of process evaluation methodology focus on specific fields of clinical practice [10-15] rather than outcome evaluation methods. The pragmatic RCT method is not explicitly addressed in existing process evaluation guidance, although some pertinent methodological issues are discussed, for example avoiding Hawthorne effects from patients participating in process evaluation interviews [4]. Nonetheless, concerns have been raised relating to pragmatic RCTs, such as the potential variability of usual care within control groups, and the potential impact of interventions beyond intervention recipients, such as to carers and family members [16]. Process evaluations present opportunities to examine and address such issues.

This review aims to provide insight into the state of process evaluation in the context of pragmatic RCTs in health services research, along with the reported value, barriers, and facilitators to conducting them. We also examine two issues identified as problematic, both from our own experience and within the process evaluation literature. Firstly, we investigate labelling, as the label 'process evaluation' has been applied to many types of study [4], and previous reviews noted inconsistent use of the term $[5,10]$. We have also anecdotally encountered confusion and multiple interpretations of the meaning of the label. Secondly, we examine accessibility as suboptimal reporting has been highlighted, such as time delay and poor linkages between trial and process evaluation results publications [4].

Our aims were, within a systematically identified sample of published pragmatic health services research RCTs, to:

1. Describe the process data reported in trial results papers

2. Describe the frequency of separate process evaluation publications

3. Describe the use of the label 'process evaluation'

4. Describe the characteristics of process evaluations

5. Synthesise reported practical barriers and facilitators to process evaluation conduct

6. Synthesise the reported values of the process evaluations

7. Describe the accessibility of process evaluation results

\section{Methods}

Similar to previous systematic reviews of process evaluations [11, 12], we used a 2-phase search process. We firstly systematically identified an index sample of journal articles reporting the primary outcome results of pragmatic RCTs evaluating health services interventions (hereafter referred to as 'trial results papers') and then systematically searched for all associated publications. Using an operational definition of process evaluation based on the MRC's framework [4], we then identified the process evaluations reported in associated publications, regardless of how they were labelled. We also identified any process data reported in index trial results papers which mapped to MRC process evaluation components. Figure 1 illustrates the methods, and Table 1 shows the MRC process evaluation components.

\section{Search strategy and inclusion and exclusion criteria}

In the first search phase, we systematically identified an index sample of pragmatic RCTs. We limited the search to a single year, 2015 (selected to allow time for related publications to appear), and to MEDLINE Core Clinical Journals to provide a feasible number of papers. We searched MEDLINE (Ovid), and the full search strategy is given in Additional file 1. 


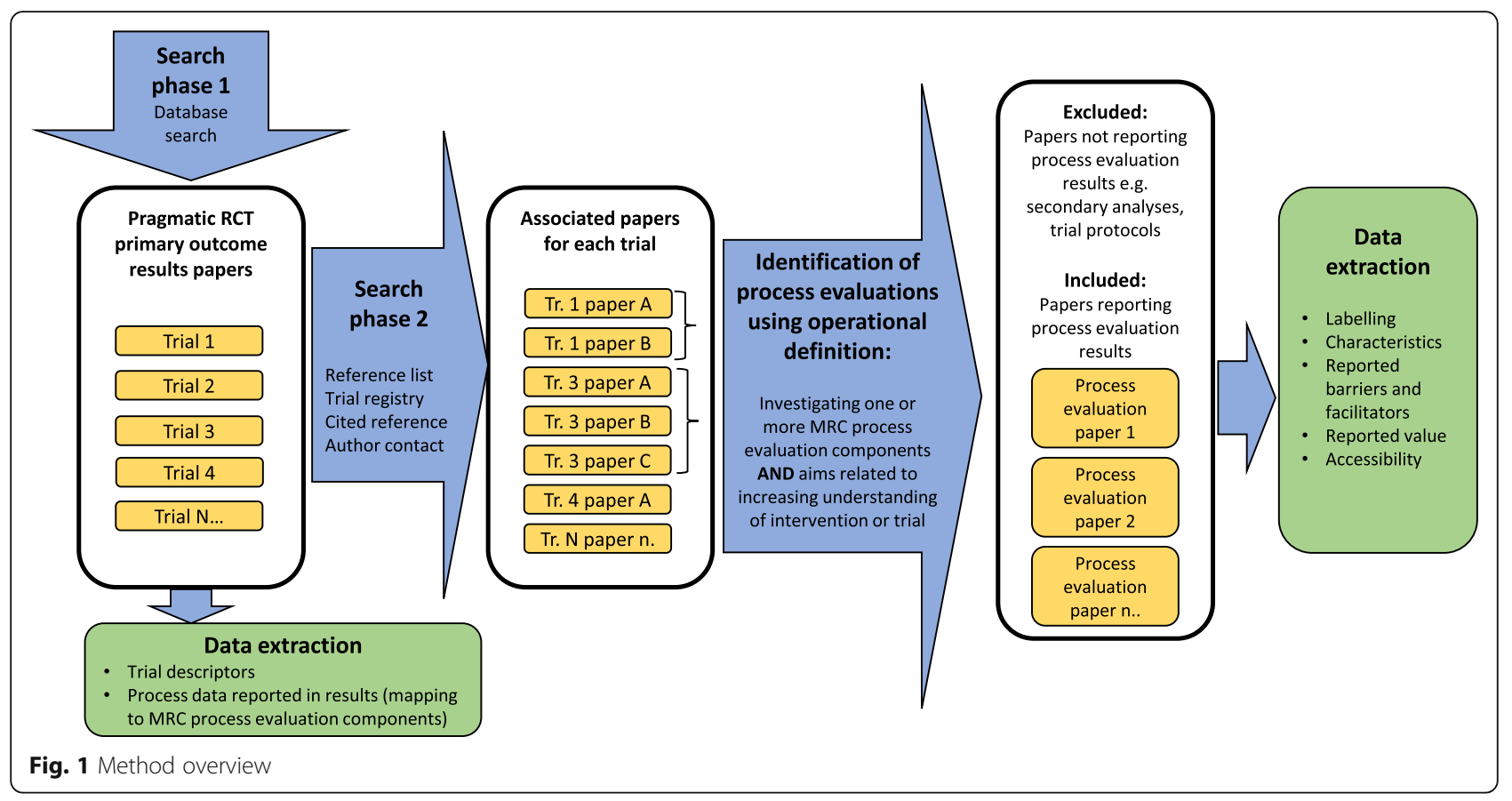

\section{Phase 1 inclusion criteria (PICOS)}

- Population: any

- Intervention: any delivered by a health service

- Comparator: any

- Outcome: any

- Study: pragmatic randomised controlled trial (defined as the use of the word 'pragmatic' to describe the RCT in the title or abstract)

\section{Phase 1 exclusion criteria}

1. Papers not reporting the primary trial outcome
2. RCTs labelled as pilot, feasibility, or implementation studies

3. Trials of health interventions not delivered within health services, for example by charities

In phase 1 , two reviewers (CF and IS) independently screened titles and abstracts against the inclusion and exclusion criteria, obtaining full texts as necessary. Any disagreements were discussed with ST and HP to reach a final decision on inclusion.

In phase 2 (see Fig. 1), citation searches for each trial results paper were conducted using both Web of Science (Clarivate Analytics) and Google Scholar. Corresponding

Table 1 MRC process evaluation components (adapted from [4], with definitions in italics where provided in original)

\section{Context}

Causal mechanisms present within the context

that act to maintain the status quo, or enhance effects
Contextual factors that shape theory

of how the intervention works
Contextual moderators

Shape, and may be shaped by, implementation, intervention mechanisms, and outcomes

\section{Implementation}

\section{Dose}

How much intervention is delivered

\section{How delivery is achieved}

The structures, resources and mechanisms

through which delivery is achieved

\section{Fidelity}

The consistency of what is implemented with the planned intervention

Reach

Extent to which target audience comes into contact with intervention

\section{Adaptations}

Alterations made to an intervention in order to achieve better contextual fit

\section{Mechanisms of impact}

Mediators

Intermediate processes which explain subsequent changes in outcome
Participant responses

How participants interact with a complex intervention 
authors were sent one reminder if we received no reply following the first contact. The searches were originally conducted, and authors contacted, in March and April 2018. Search phase 2 was updated in December 2019 apart from author contact.

We used an operational definition of 'process evaluation' to identify papers for inclusion regardless of how they were labelled by the study authors. As shown in Fig. 1, included studies investigated one or more MRC process evaluation components and (to distinguish them from trial secondary analyses or substudies) were aimed at increasing understanding of the intervention or trial. One reviewer (CF) screened all publications and discussed all considered to possibly be process evaluations with $\mathrm{HP}$ and ST in a consensus meeting to agree the final sample of process evaluations.

Several index trials were funded by the UK National Institute for Health Research's Health Technology Assessment (HTA) programme. This programme requires results to be published as a monograph in the Health Technology Assessment journal, additional to any other journal publications. We therefore reviewed the full texts of all HTA monographs to check for process evaluation results.

\section{Data extraction and analysis}

As this was a review of methodology rather than findings, we did not conduct any appraisal of quality of the included process evaluation studies. We extracted quantitative data to an Excel database and conducted descriptive analysis using SPSS v25. We extracted qualitative data as sections of text from PDFs of publications and used NVivo v11 for data management and to aid thematic analysis.

Where the methods or results from a single trial or process evaluation were reported in more than one publication (e.g. HTA monograph and separate journal paper), we extracted all available data from all publications but treated the publications as a single case. CF extracted and analysed all data independently, apart from the MRC process evaluation components as detailed below.

\section{Data extracted from the trial results papers}

We extracted descriptors of all trials, and the data fields and their operationalisation are shown in Additional file 2. We mapped data items reported in the results sections to the MRC process evaluation framework [4] (see Table 1) to identify process data within the trial results papers. For example, a trial flow diagram (process data item) mapped to the process evaluation component 'reach'. For each trial, we recorded whether each process evaluation component was reported in the trial results paper at least once. We piloted this process, and as the MRC guidance does not provide clear definitions for some components, we made a list of the types of data which mapped to each component (for example subgroup analyses mapped to 'contextual moderators'). Three reviewers (CF, GF, and IS) independently extracted data from the first three trials, compared results, and agreed initial mappings. We used these to extract data from four further trials and again compared and discuss findings. CF then extracted data for the remaining trials, discussing any new mappings or uncertainties with the other authors.

\section{Data extracted from process evaluation publications}

Table 2 shows the outcomes extracted for each process evaluation publication. O'Cathain et al. [17] noted that the value of qualitative research within RCTs is often not clearly articulated in publications, and we noted the same during scoping this review. We therefore operationalised 'reported value' as any reported rationales for undertaking a process evaluation, or any reported implications of having undertaken it or of its findings. This allowed us to capture any anticipated or observed benefits of the process evaluation or use of the knowledge it produced.

A completed PRISMA checklist is in Additional file 3.

Table 2 Data outcomes for process evaluation publications

\begin{tabular}{|c|c|c|}
\hline Review objective & Type of data & Outcomes \\
\hline Labelling & Quantitative & $\begin{array}{l}\text { - Use of label 'process evaluation' anywhere in the set of papers for the trial } \\
\text { - Use of keyword 'process evaluation' for indexing }\end{array}$ \\
\hline Characteristics & Quantitative & $\begin{array}{l}\text { - Process evaluation components (mapped from aims and qualitative findings) } \\
\text { - Whether processes related to the intervention or trial } \\
\text { - Methodology } \\
\text { - Data collection method }\end{array}$ \\
\hline Reported barriers and facilitators & Qualitative & - Practical issues relating to designing or operationalising the process evaluation \\
\hline Reported value & Qualitative & - Reported rationales for undertaking, or implications of the process evaluation \\
\hline Accessibility & Quantitative & $\begin{array}{l}\text { - Publishing journal } \\
\text { - Time to publication from trial results paper } \\
\text { - Search method required to locate paper } \\
\text { - Mention of the process evaluation in trial results paper } \\
\text { - Where in paper the trial first named or referenced } \\
\text { - Inclusion in trial registry }\end{array}$ \\
\hline
\end{tabular}




\section{Results}

Figure 2 shows the results of search phases 1 and 2. The first search phase yielded 31 journal articles reporting primary outcome results from pragmatic RCTs, and the second phase located 133 associated publications. We categorised 21 of these 133 associated publications as

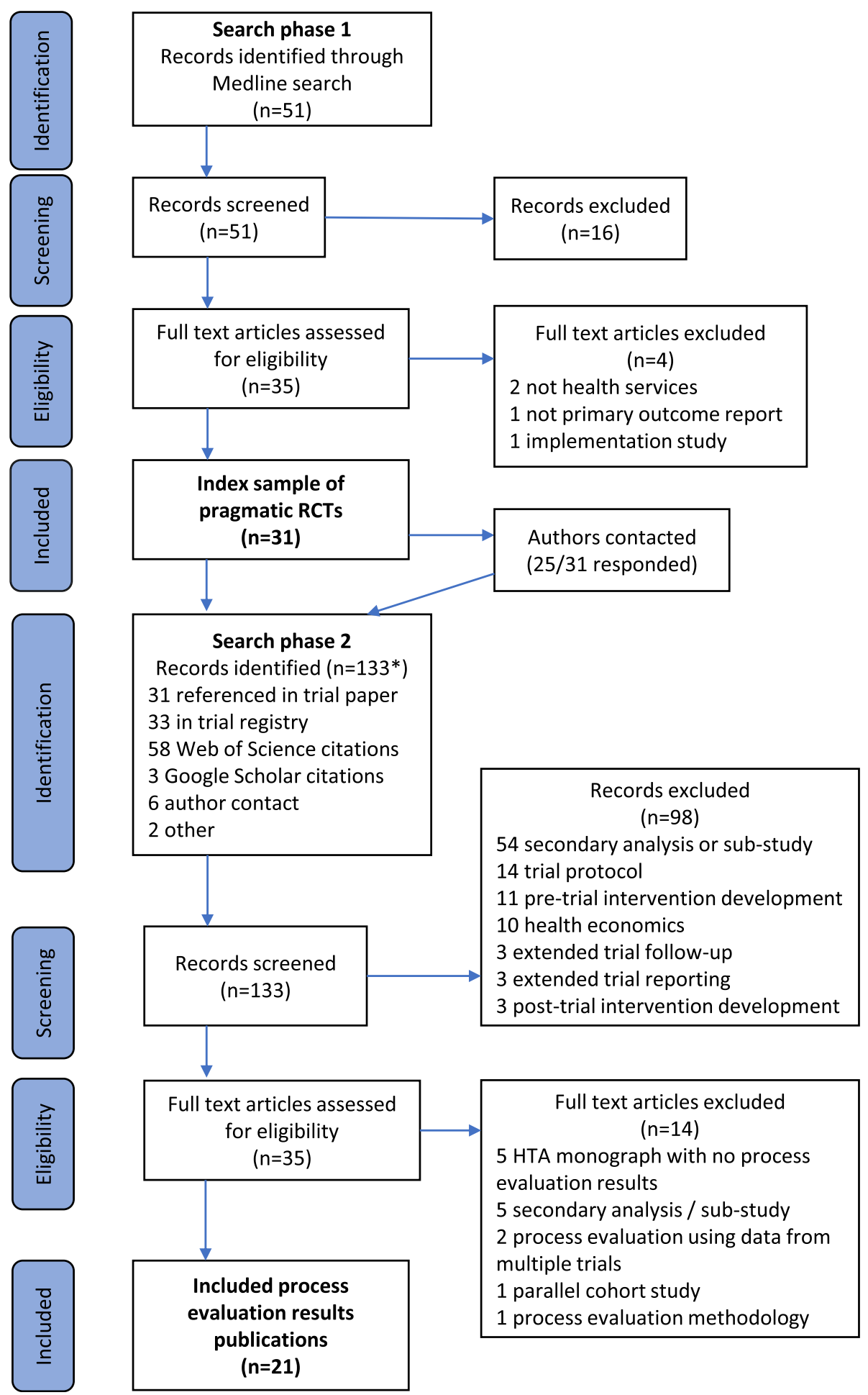

Fig. 2 Adapted PRISMA flow diagram [18]. The asterisk indicates searches conducted in order stated and each record included only under search method first found 
process evaluation results. These covered 17 separate process evaluation studies, as some were published in more than one paper.

\section{Characteristics of the sample of pragmatic RCTs}

The sample of pragmatic RCTs $(n=31)$ was highly variable in terms of intervention and trial characteristics (see Additional file 4 for details of the RCTs). They covered 20 different clinical specialties and 17 different combinations of professionals involved in intervention delivery. Most interventions (28/31) were received by patients only, with the remainder directed at staff or staff and patients. Table 3 summarises further characteristics of the included trials.

\section{Process evaluations}

Twelve of the 31 pragmatic RCTs had at least one associated publication which we classified as reporting process evaluation results. We identified 17 distinct process evaluation studies, with two trials $[19,20]$ having three process evaluations and one trial [21] having two process evaluations. Although it is likely

Table 3 Characteristics of the index sample of pragmatic RCTs

\begin{tabular}{|c|c|c|c|}
\hline Randomisation level & & Comparator & \\
\hline Individual & 25 & Usual care & 15 \\
\hline Cluster & 6 & Other intervention(s) & 10 \\
\hline & & Stepped-wedge control period & 2 \\
\hline Design & & Comparing two settings & 1 \\
\hline 2-arm & 22 & Comparing two deliverers & 1 \\
\hline Non-inferiority (2-arm) & 4 & No intervention & 1 \\
\hline 3-arm & 3 & Sham clinical procedure & 1 \\
\hline Crossover & 1 & & \\
\hline Stepped-wedge & 1 & Publishing journal & \\
\hline & & British Medical Journal & 7 \\
\hline Primary outcome result & & Lancet & 7 \\
\hline No evidence of effect & 15 & JAMA & 5 \\
\hline Evidence of effect & 11 & Canadian Medical Association Journal & 2 \\
\hline Non-inferiority trial & 4 & JAMA Pediatrics & 2 \\
\hline Unclear & 1 & Critical Care Medicine & 1 \\
\hline & & Gut & 1 \\
\hline Funder & & JAMA Internal Medicine & 1 \\
\hline Public & 25 & JAMA Psychiatry & 1 \\
\hline Multiple funders & 3 & Journal of Allergy and Clinical Immunology & 1 \\
\hline Charity & 1 & New England Journal of Medicine & 1 \\
\hline Independent Organisation & 1 & Nursing Research & 1 \\
\hline Not reported & 1 & The American Journal of Psychiatry & 1 \\
\hline Type of intervention & & Country & \\
\hline Pharmacological treatment strategy & 9 & UK & 12 \\
\hline Clinical procedure & 4 & USA & 8 \\
\hline Therapy intervention & 4 & Australia & 3 \\
\hline Clinical treatment strategy & 3 & Netherlands & 2 \\
\hline Model of care provision & 3 & Brazil & 1 \\
\hline Reminder system & 3 & Canada & 1 \\
\hline Health promotion & 3 & France & 1 \\
\hline Medical device & 2 & France, Belgium and Switzerland & 1 \\
\hline & & Hong Kong & 1 \\
\hline & & North America ${ }^{a}$ & 1 \\
\hline
\end{tabular}

${ }^{\mathrm{a}}$ Countries not specified in original article 
that these multiple process evaluation studies in the same trials formed part of one overall process evaluation, as each was presented as a distinct study, we extracted data from each individually. The 17 process evaluation studies were published across 21 publications, as some were published in both a journal article and HTA monograph.

The 17 process evaluation studies are listed in Table 4.

\section{Labelling}

In the trial results papers, the label 'process evaluation' was never used to describe the process data. Five trials $[19,43-46]$ used variations of the labels 'process outcome' or 'process measure' for some data, although this use was infrequent and inconsistent.

Only three of the 17 studies we classified as process evaluations were labelled as process evaluations [30, 31, $33,34]$. One further study was not explicitly labelled as a process evaluation but this was implied as the MRC process evaluation guidance was cited as a rationale for undertaking it [28]. Only one of the three studies labelled as 'process evaluation' was clearly labelled as such in the article title [31]. One was described as 'informing a process evaluation' in the main article text [30]. The other was referred to as a process evaluation by the trial results paper [47], but not labelled as such in the journal article [33] or HTA monograph [34] reporting it.

Notably, one trial [19] had three qualitative studies published in the same journal: a qualitative interview study labelled as 'a process evaluation' [31], a qualitative questionnaire study reported as 'informing the process evaluation' [30], and a qualitative interview study labelled as a 'qualitative evaluation' [29]. However, the articles indicated that the studies were interlinked and formed a 'sequential mixed-methods study' [31].

None of the journal articles reporting process evaluation results $(n=16)$ used the keyword 'process evaluation'.

\section{Characteristics of process evaluation studies}

Of the 17 process evaluation studies identified, nine were quantitative $[22,24-28,32,37,39,40]$ and eight qualitative [23, 29-31, 34-36, 38, 41, 42]. The three labelled as process evaluations were all qualitative [30, 31, $33,34]$. There were a variety of data collection methods as can be seen in Table 4, with the use of trial data $(n=$ $5)$, interviews $(n=4)$, and questionnaires $(n=3)$ being the most common. The reporting articles of three quantitative process evaluations [25, 27, 37] also presented detailed descriptions of trial or process evaluation methods.

Twelve process evaluations evaluated only intervention processes $[22,24,28-31,33-36,38-42]$, and five evaluated both trial and intervention processes [23, 25-27, 32, 37]. Of the latter, one explored patients' experiences of trial participation qualitatively [23] and two described in detail the trial processes undertaken to ensure fidelity [27, 37]. One investigated the trial processes for defining the pragmatic RCT trial population, by undertaking independent assessment of the radiographs used by recruiting surgeons to determine trial inclusion [25]. Another investigated the impact of surgeon and patient treatment preferences on trial recruitment and adherence to trial follow-up [32]. Further details of the processes evaluated by all 17 studies can be found in Table 4 .

\section{Process evaluation components reported in the trial results papers and process evaluation papers}

All 31 pragmatic RCTs reported process data in their trial results paper(s), with a median of five different MRC process evaluation components $(\mathrm{IQR}=3$; range 1-9) reported at least once per trial results paper. Further details can be found in Additional file 4.

Figure 3 shows the percentages of pragmatic RCTs $(n=31)$ reporting each MRC process evaluation component in their trial results paper(s) and the percentages of process evaluation studies $(n=17)$ reporting each component.

Although we found most of the identified process evaluation components to be reported in the main trial papers and/or in papers labelled process evaluations, the component 'how delivery is achieved' was only reported in process evaluation papers and 'dose' was only reported in trial results papers. The other 'implementation' components-'fidelity', 'adaptations', and 'reach' were more frequently reported in the trial results papers than the process evaluation papers.

Additional file 4 lists the included 31 pragmatic RCT results papers, and the process evaluation components reported in each. Additional file 5 shows the data items we mapped to each process evaluation component in the trial results papers and process evaluation papers.

\section{Barriers and facilitators to conducting process evaluations} We identified three main themes of reported barriers and facilitators to conducting process evaluation within pragmatic RCTs, shown in Fig. 4. These themes were collecting complete and accurate data in health services settings, recruiting the process evaluation participants, and complex regulatory systems (only barriers identified within this theme).

\section{Reported value of the process evaluation studies}

We identified three main themes relating to the reported value of the process evaluation: (1) whether the process evaluation added value to the intervention, (2) whether the process added value to the trial, or (3) whether the process evaluation's value related to something external 
Table 4 Included process evaluation studies

\begin{tabular}{|c|c|c|c|c|c|}
\hline Reference(s) & Description of process evaluation & $\begin{array}{l}\text { Methodology and data } \\
\text { collection methods }\end{array}$ & $\begin{array}{l}\text { Intervention } \\
\text { or trial } \\
\text { processes }\end{array}$ & $\begin{array}{l}\text { Process evaluation } \\
\text { components }\end{array}$ & $\begin{array}{l}\text { Labelled as } \\
\text { process } \\
\text { evaluation } \\
\end{array}$ \\
\hline Ball 2018 [22] & $\begin{array}{l}\text { Investigated the effect of mild } \\
\text { cognitive impairment in } \\
\text { participants on intervention } \\
\text { outcome }\end{array}$ & $\begin{array}{l}\text { Quantitative } \\
\text { Trial dataset }\end{array}$ & Intervention & Contextual moderators & No \\
\hline Clark 2015 [23] & $\begin{array}{l}\text { Explored patient perceptions } \\
\text { of the acceptability of } \\
\text { intervention in both groups, } \\
\text { and motivations for agreeing } \\
\text { or refusing to participate in } \\
\text { the trial }\end{array}$ & $\begin{array}{l}\text { Qualitative } \\
\text { Interviews }\end{array}$ & $\begin{array}{l}\text { Intervention } \\
\text { and trial }\end{array}$ & $\begin{array}{l}\text { Participant responses } \\
\text { Reach } \\
\text { Contextual moderators } \\
\text { Unintended consequences } \\
\text { Causal mechanisms in } \\
\text { context }\end{array}$ & No \\
\hline Grubbs 2015 [24] & $\begin{array}{l}\text { Investigated which factors } \\
\text { predicted patient uptake of } \\
\text { an element of the } \\
\text { intervention found to mediate } \\
\text { the primary outcome }\end{array}$ & $\begin{array}{l}\text { Quantitative } \\
\text { Medical record review }\end{array}$ & Intervention & Contextual moderators & No \\
\hline Handoll 2016 [25] & \multirow{2}{*}{$\begin{array}{l}\text { Described how the intended } \\
\text { fracture population was } \\
\text { practically achieved in } \\
\text { pragmatic RCT, including } \\
\text { results of formal independent } \\
\text { assessment and classification } \\
\text { of trial fractures }\end{array}$} & \multirow{2}{*}{$\begin{array}{l}\text { Quantitative } \\
\text { Detailed author } \\
\text { description } \\
\text { Trial dataset }\end{array}$} & \multirow{2}{*}{$\begin{array}{l}\text { Intervention } \\
\text { and trial }\end{array}$} & \multirow[t]{2}{*}{ Reach } & \multirow[t]{2}{*}{ No } \\
\hline Handoll 2015 [26] & & & & & \\
\hline Handoll 2014 [27] & \multirow[b]{2}{*}{$\begin{array}{l}\text { Described processes } \\
\text { undertaken to ensure usual } \\
\text { care received by both } \\
\text { groups in trial was good } \\
\text { quality and comparable, } \\
\text { including results of } \\
\text { methods described }\end{array}$} & \multirow{2}{*}{$\begin{array}{l}\text { Quantitative } \\
\text { Detailed author } \\
\text { description } \\
\text { Deliverer self-report }\end{array}$} & \multirow{2}{*}{$\begin{array}{l}\text { Intervention } \\
\text { and trial }\end{array}$} & \multirow{2}{*}{$\begin{array}{l}\text { How delivery is } \\
\text { achieved } \\
\text { Fidelity }\end{array}$} & \multirow[t]{2}{*}{ No } \\
\hline Handoll 2015 [26] & & & & & \\
\hline Hall 2017 [28] & $\begin{array}{l}\text { Investigated mediators of } \\
\text { intervention } \\
\text { outcome }\end{array}$ & $\begin{array}{l}\text { Quantitative } \\
\text { Trial dataset }\end{array}$ & Intervention & Mediators & No \\
\hline Hill 2016 [29] & $\begin{array}{l}\text { Explored perceptions of ward } \\
\text { staff about how intervention } \\
\text { contributed to outcome, } \\
\text { and experience of intervention } \\
\text { being delivered on their ward }\end{array}$ & $\begin{array}{l}\text { Qualitative } \\
\text { Focus groups }\end{array}$ & Intervention & $\begin{array}{l}\text { How delivery is achieved } \\
\text { Participant responses } \\
\text { Contextual moderators } \\
\text { Causal mechanisms in } \\
\text { context } \\
\text { Contextual factors shaping } \\
\text { intervention theory }\end{array}$ & No \\
\hline Hill 2016 [30] & $\begin{array}{l}\text { Explored patient experiences } \\
\text { of intervention and perceived } \\
\text { barriers to engagement }\end{array}$ & $\begin{array}{l}\text { Qualitative } \\
\text { Semi-structured } \\
\text { questionnaires }\end{array}$ & Intervention & $\begin{array}{l}\text { Participant responses } \\
\text { Causal mechanisms in } \\
\text { context } \\
\text { Contextual factors shaping } \\
\text { intervention theory }\end{array}$ & Yes \\
\hline Hill 2015 [31] & $\begin{array}{l}\text { Explored perceptions of } \\
\text { intervention deliverers of } \\
\text { delivering intervention } \\
\text { and how the intervention } \\
\text { worked }\end{array}$ & $\begin{array}{l}\text { Qualitative } \\
\text { Focus groups, interview, } \\
\text { field notes, intervention } \\
\text { notes }\end{array}$ & Intervention & $\begin{array}{l}\text { How delivery is achieved } \\
\text { Contextual factors shaping } \\
\text { intervention theory } \\
\text { Participant responses } \\
\text { Causal mechanisms in } \\
\text { context }\end{array}$ & Yes \\
\hline Keding 2019 [32] & \multirow{2}{*}{$\begin{array}{l}\text { Explored how patient and } \\
\text { surgeon treatment } \\
\text { preferences impacted } \\
\text { recruitment, trial conduct, } \\
\text { and patient outcomes }\end{array}$} & \multirow{2}{*}{$\begin{array}{l}\text { Quantitative } \\
\text { Trial dataset }\end{array}$} & \multirow{2}{*}{$\begin{array}{l}\text { Intervention } \\
\text { and trial }\end{array}$} & \multirow{2}{*}{$\begin{array}{l}\text { Reach } \\
\text { Participant responses } \\
\text { Contextual moderators }\end{array}$} & \multirow[t]{2}{*}{ No } \\
\hline Handoll 2015 [26] & & & & & \\
\hline Knowles 2015 [33] & \multirow{2}{*}{$\begin{array}{l}\text { Explored patient experiences } \\
\text { of the intervention, including } \\
\text { acceptability, ease of use, } \\
\text { barriers to engagement, } \\
\text { content, accessibility, and } \\
\text { support. Also explored }\end{array}$} & \multirow{2}{*}{$\begin{array}{l}\text { Qualitative } \\
\text { Interviews }\end{array}$} & \multirow[t]{2}{*}{ Intervention } & \multirow{2}{*}{$\begin{array}{l}\text { Participant responses } \\
\text { How delivery is achieved } \\
\text { Reach } \\
\text { Causal mechanisms in context } \\
\text { Contextual moderators } \\
\text { Unintended consequences }\end{array}$} & \multirow[t]{2}{*}{ Yes } \\
\hline Littlewood 2015 [34] & & & & & \\
\hline
\end{tabular}


Table 4 Included process evaluation studies (Continued)

\begin{tabular}{|c|c|c|c|c|c|}
\hline Reference(s) & Description of process evaluation & $\begin{array}{l}\text { Methodology and data } \\
\text { collection methods }\end{array}$ & $\begin{array}{l}\text { Intervention } \\
\text { or trial } \\
\text { processes }\end{array}$ & $\begin{array}{l}\text { Process evaluation } \\
\text { components }\end{array}$ & $\begin{array}{l}\text { Labelled as } \\
\text { process } \\
\text { evaluation }\end{array}$ \\
\hline & $\begin{array}{l}\text { healthcare professional } \\
\text { perceptions of feasibility } \\
\text { and which patients' } \\
\text { intervention most suited to. }\end{array}$ & & & $\begin{array}{l}\text { Contextual factors shaping } \\
\text { intervention theory }\end{array}$ & \\
\hline Nichols 2017 [35] & \multirow{2}{*}{$\begin{array}{l}\text { Explored experiences of } \\
\text { patients about intervention, } \\
\text { with focus on patient } \\
\text { adherence, and how } \\
\text { changed over time }\end{array}$} & \multirow{2}{*}{$\begin{array}{l}\text { Qualitative } \\
\text { Interviews (longitudinal) }\end{array}$} & \multirow[t]{2}{*}{ Intervention } & \multirow{2}{*}{$\begin{array}{l}\text { Participant responses } \\
\text { Causal mechanisms in } \\
\text { context } \\
\text { Contextual moderators } \\
\text { How delivery is achieved }\end{array}$} & \multirow[t]{2}{*}{ No } \\
\hline Williams 2015 [36] & & & & & \\
\hline Novak 2015 [37] & $\begin{array}{l}\text { Investigated whether and } \\
\text { how trial sites supplied } \\
\text { thawed plasma in a } \\
\text { timely manner }\end{array}$ & $\begin{array}{l}\text { Quantitative } \\
\text { Detailed author } \\
\text { description } \\
\text { Observation, reports } \\
\text { from sites }\end{array}$ & $\begin{array}{l}\text { Intervention } \\
\text { and trial }\end{array}$ & $\begin{array}{l}\text { Fidelity } \\
\text { How delivery is achieved }\end{array}$ & No \\
\hline Sands 2016 [38] & $\begin{array}{l}\text { Explored how the flexible } \\
\text { complex intervention was } \\
\text { delivered in real-world } \\
\text { complex settings }\end{array}$ & $\begin{array}{l}\text { Qualitative } \\
\text { Trial dataset }\end{array}$ & Intervention & $\begin{array}{l}\text { How delivery is achieved } \\
\text { Adaptations } \\
\text { Contextual moderators } \\
\text { Participant responses } \\
\text { Unintended consequences } \\
\text { Contextual factors shaping } \\
\text { intervention theory } \\
\text { Fidelity }\end{array}$ & No \\
\hline Saville 2016 [39] & $\begin{array}{l}\text { Explored preferences and } \\
\text { experiences of intervention } \\
\text { deliverers about various } \\
\text { aspects of intervention }\end{array}$ & $\begin{array}{l}\text { Quantitative } \\
\text { Questionnaire }\end{array}$ & Intervention & How delivery is achieved & No \\
\hline Tjia 2017 [40] & $\begin{array}{l}\text { Investigated patients' } \\
\text { perceptions of benefits and } \\
\text { drawbacks of intervention }\end{array}$ & $\begin{array}{l}\text { Quantitative } \\
\text { Questionnaire }\end{array}$ & Intervention & Participant responses & No \\
\hline Vennik 2019 [41] & \multirow{2}{*}{$\begin{array}{l}\text { Explored views and } \\
\text { experiences of parents and } \\
\text { practice nurses of } \\
\text { intervention and usual care }\end{array}$} & \multirow{2}{*}{$\begin{array}{l}\text { Qualitative } \\
\text { Interviews }\end{array}$} & \multirow[t]{2}{*}{ Intervention } & \multirow{2}{*}{$\begin{array}{l}\text { Participant responses } \\
\text { How delivery is achieved } \\
\text { Contextual factors shaping } \\
\text { intervention theory } \\
\text { Causal mechanisms in } \\
\text { context } \\
\text { Unintended consequences }\end{array}$} & \multirow[t]{2}{*}{ No } \\
\hline Williamson 2016 [42] & & & & & \\
\hline
\end{tabular}

to the trial and intervention. Figure 5 shows the main themes and subthemes, and Table 5 shows the number of process evaluations mentioning each subtheme and examples of data relating to each subtheme. A full table of all data for each subtheme is in Additional file 6 .

\section{Reported value specifically relating to the pragmatic RCT} The reports of three process evaluations belonging to the same trial [25-27, 32] (not labelled as process evaluations) discussed the pragmatic nature of the trial and the process evaluations' contributions in detail. All highlighted how they supported validity of trial results, by addressing potentially problematic areas of the pragmatic trial design. In one process evaluation $[25,26]$, the authors report it confirmed that the achieved trial sample was pragmatic as intended, and endorsed the pragmatic methods used to determine trial eligibility. In another [26, 27], the authors describe how it provided evidence of a good standard of, and therefore comparable, real-world clinical practice in the intervention and usual care delivered in the pragmatic trial across trial sites. In the final process evaluation [26, $32]$, the impact of patient and surgeon preference on internal and external validity is investigated, acknowledging that this is a threat to the validity of trial findings from the real-world setting.

No other reports explicitly discussed the pragmatic nature of the RCT. However, one process evaluation [38] used a qualitative content analysis to 'describe the pragmatic reality' of intervention delivery, and its authors emphasise that this was important to allow post-trial replication of a flexible intervention with a large potential variability of delivery in a complex setting. In the report of a qualitative interview study with intervention recipients and providers [42], the authors highlight that these process evaluation data provide real-life insights to aid post-trial implementation. 


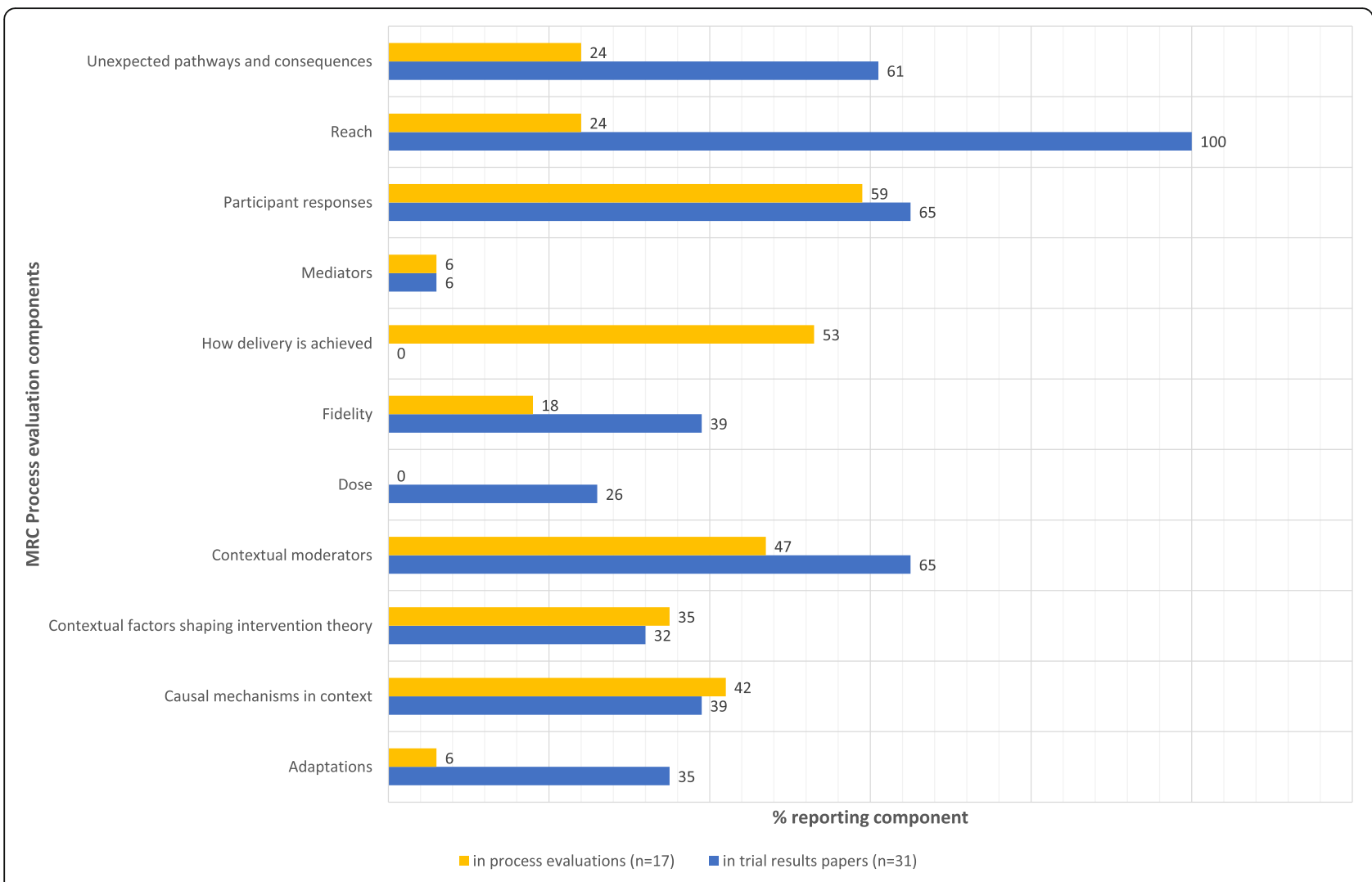

Fig. $3 \mathrm{MRC}$ process evaluation components reported in the trial results papers and process evaluations

\section{Accessibility of process evaluation studies}

Thirteen of the 17 process evaluation studies [22, 24, 28-32, 35-38, 40-42] had no mention in their corresponding index trial results papers.

Journal articles reporting process evaluation results $(n=16)$ were published a median of 15.5 months (range - 3-42; IQR 18.25) after the corresponding index trial results papers. None was published in the same journals as the trial results papers. Two trials had multiple process evaluation studies published in the same journals [25, 27, 29-31]. Twelve of the 16 process evaluation journal articles [22, 28-32, 35, 37-39, 41] were not included in the trial registry entries. A forward citation search of the index trial results paper was required to locate $9 / 16$ of the process evaluation journal articles. Two process evaluation journal articles [37, 38] did not appear in the trial results paper, trial registry, or forwards citation searches. These were located by chance before contacting authors as they were mentioned in other papers associated with the trials. All process evaluation journal articles named or referenced the corresponding trial; however, 9/ 16 did not name or explicitly link it to the trial in the title or abstract [22, 24, 25, 29-31, 39-41].

Six of the 12 trials with process evaluation(s) were funded by the UK NIHR HTA programme and published an HTA monograph [23, 26, 34, 36, 42, 48]. One process evaluation was only reported in the HTA monograph [23], not a journal article. Six process evaluation studies were published at least in part in both a journal article $[25,27,32,33,35,41]$ and HTA monograph [26, $34,36,42]$. Two process evaluations were part of HTAfunded trials; however, results were not reported in the HTA monographs, only in journal articles [28, 38].

The five HTA monographs reporting process evaluation findings [23, 26, 34, 36, 42] all appeared in the trial registry and were published a median of 1 month (IQR 3 ; range 0-4) after the trial results papers. Combining publication data for journal articles and HTA monographs therefore improved these aspects of accessibility for the whole sample of process evaluations $(n=17)$. If the earliest of the HTA monograph and journal article for each process evaluation is included, process evaluation studies $(n=17)$ were published a median of 5 months (range 0-36; IQR 15.5) after the trial results. Similarly, 9/17 process evaluations were published in a publication included in the trial registry entry.

\section{Discussion}

\section{Summary of findings}

We identified a range of reported benefits of process evaluations to the interventions they evaluated, to the associated pragmatic RCTs, and beyond to wider 

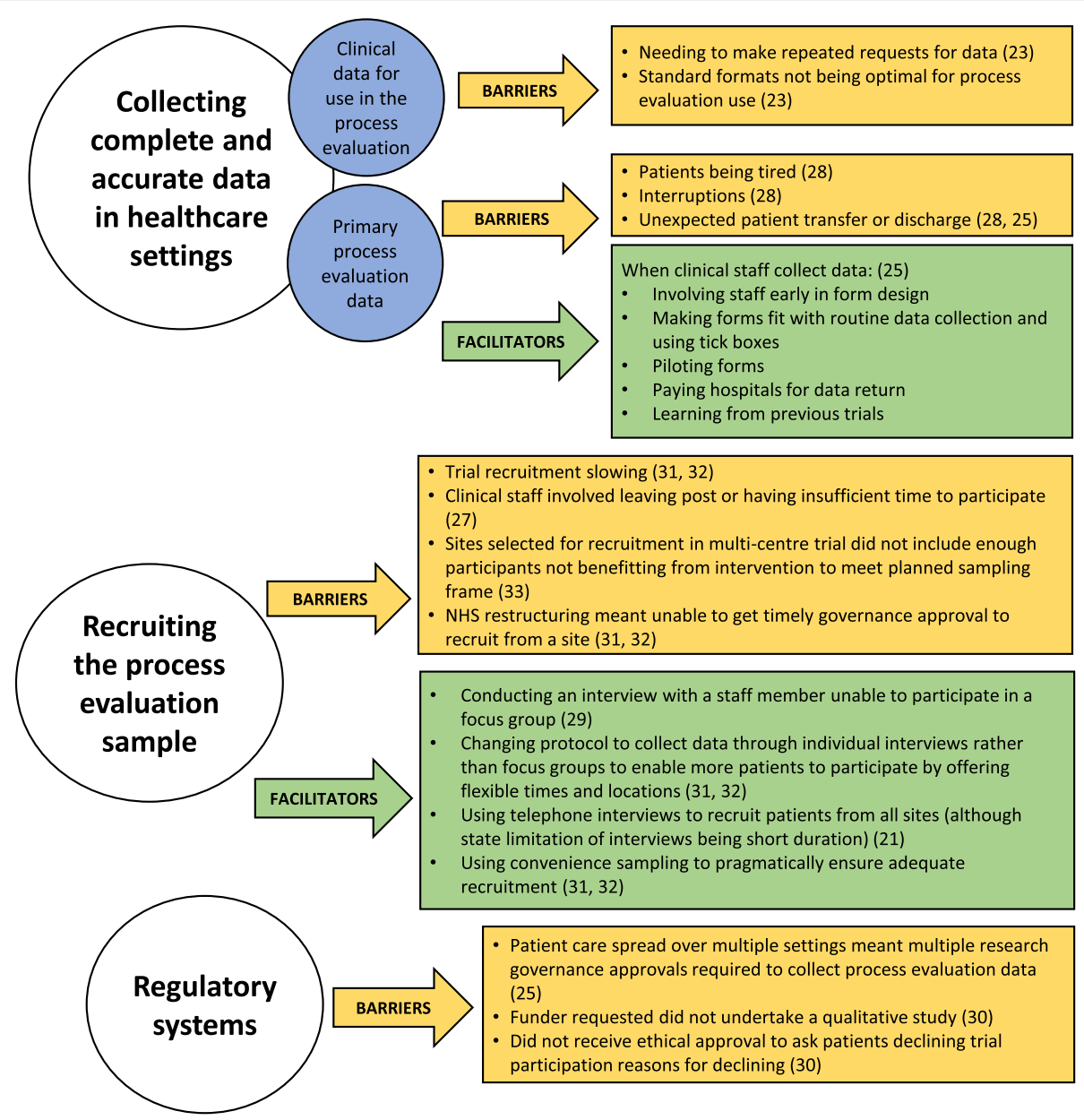

Fig. 4 Reported barriers and facilitators

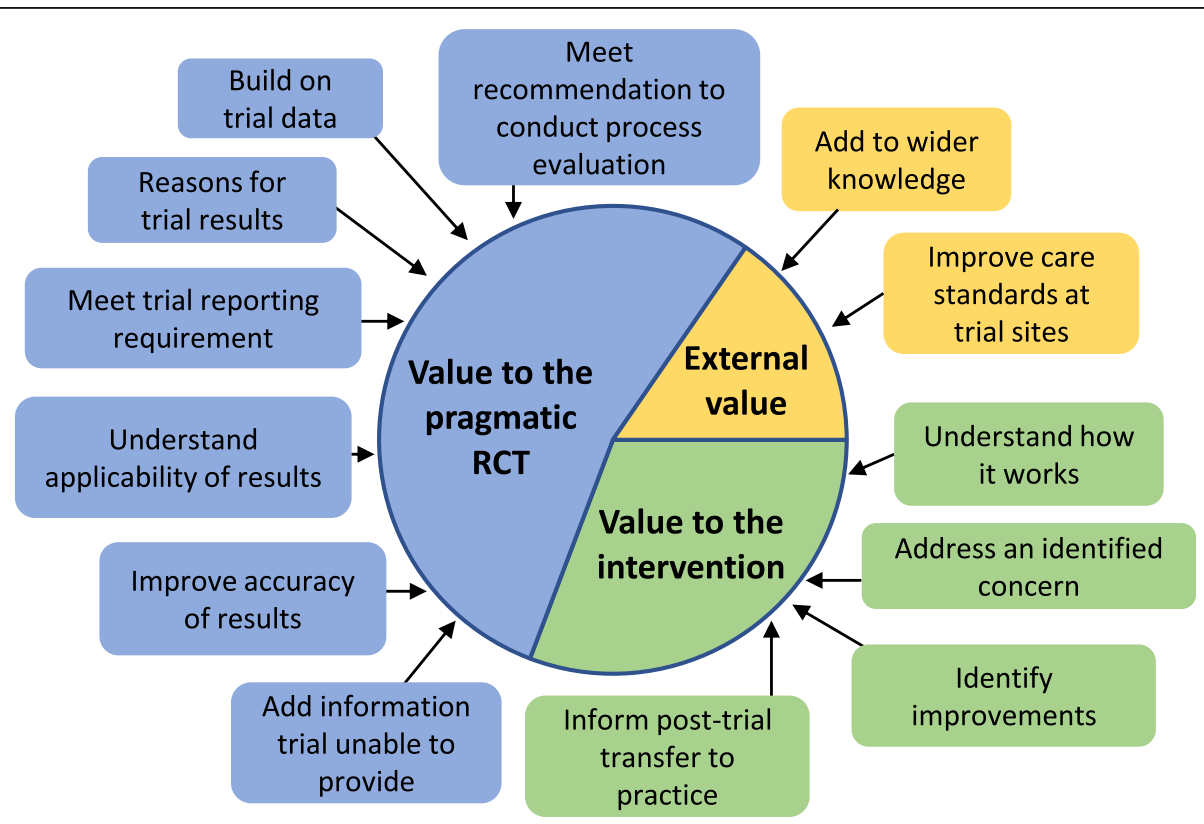

Fig. 5 Synthesis of reported values of process evaluation studies 
Table 5 Reported value subthemes

\begin{tabular}{|c|c|c|}
\hline Subtheme & $\begin{array}{l}\text { Number of process evaluations } \\
\text { reporting this value }(n=17)\end{array}$ & Examples of reported values in subtheme \\
\hline Adding to wider knowledge & 16 & $\begin{array}{l}\text { - Informing future trial design }[23,25,27,28,32,33,38] \\
\text { - Improving future design of similar interventions }[22,24,33]\end{array}$ \\
\hline $\begin{array}{l}\text { Informing post-trial transfer of intervention } \\
\text { to practice }\end{array}$ & 15 & $\begin{array}{l}\text { - Providing evidence of feasibility }[28,33] \\
\text { - Highlighting potential disadvantages of intervention to } \\
\text { facilitate consent discussions with patients [23] }\end{array}$ \\
\hline Identifying intervention improvements & 10 & $\begin{array}{l}\text { - Adding stronger monitoring protocols to promote adherence } \\
\text { [33] } \\
\text { - Recommendation to research effectiveness over time [29] }\end{array}$ \\
\hline Providing reasons for trial results & 8 & $\begin{array}{l}\text { - Reasons for non-positive results }[33,38] \\
\text { - Reasons for positive results }[28-31,35]\end{array}$ \\
\hline $\begin{array}{l}\text { Addressing an identified concern about } \\
\text { the intervention }\end{array}$ & 7 & $\begin{array}{l}\text { - Concern about the effect of cognitive impairment on } \\
\text { effectiveness [22] } \\
\text { - Concern about participant adherence }[33,35]\end{array}$ \\
\hline $\begin{array}{l}\text { Adding information not provided by the } \\
\text { trial }\end{array}$ & 6 & $\begin{array}{l}\text { - Participant and deliverer experiences and perceptions }[23,35] \\
\text { - Nuance and context [23] }\end{array}$ \\
\hline Increasing accuracy of trial results & 6 & $\begin{array}{l}\text { - Investigating threats to internal validity [26] } \\
\text { - Accurately defining trial population [25] }\end{array}$ \\
\hline Understanding how the intervention works & 4 & $\begin{array}{l}\text { - Understanding what was delivered in a flexible intervention } \\
\text { [38] } \\
\text { - Mechanisms of impact [28] }\end{array}$ \\
\hline Building on trial data & 2 & - Exploring findings of subgroup analysis [29] \\
\hline Understanding applicability of trial results & 2 & $\begin{array}{l}\text { - Evaluating whether intended pragmatic trial population } \\
\text { achieved [25] }\end{array}$ \\
\hline Improving usual care at trial sites & 1 & • Highlighting gaps in current care provision [27] \\
\hline $\begin{array}{l}\text { Meeting pragmatic } \mathrm{RCT} \text { reporting } \\
\text { requirements }\end{array}$ & 1 & $\begin{array}{l}\text { - Adhere to reporting standards for pragmatic and non- } \\
\text { pharmacological trials [27] }\end{array}$ \\
\hline $\begin{array}{l}\text { Meeting recommendation to conduct } \\
\text { process evaluation }\end{array}$ & 1 & • Following MRC recommendations [28] \\
\hline
\end{tabular}

knowledge. Nonetheless, only approximately one third (12/31) of the pragmatic RCTs included in this review had published process evaluations. However, many data items were reported in trial results papers, which we mapped to MRC-defined process evaluation components. Very few (3/17) studies which we categorised as process evaluations were labelled as such, and the label was used inconsistently in those which did employ it. The 17 process evaluations utilised a variety of qualitative and quantitative methods and examined a wide range of process evaluation components, including trial processes. We identified several practical barriers and facilitators to their design and conduct and found visibility and accessibility of process evaluation results were often suboptimal. We now discuss these findings and draw recommendations, with a summary of recommendations presented in Table 6.

Value, inclusion, and definitions

In the design and evaluation of complex interventions, there is increasing recognition that process evaluations are necessary [2], and calls for their routine inclusion
[1]. In support of this, we identified a wide range of ways in which process evaluations may add value to interventions and trials. Some of the values we identified resonate with previous reviews [10, 49], such as informing post-trial implementation of interventions into practice and contributing to wider knowledge. We also identified some less recognised, for example improving the standard of care at trial sites by exposing gaps in current care provision [27]. These findings are useful to researchers to aid reflection on the potential value of process evaluations, and articulation of this to stakeholders. We did not investigate whether the reported value of the process evaluations related to whether or not the associated trial showed evidence of effect; however, this would be useful to include in future reviews.

Our findings suggest that, at least in 2015, process evaluations were far from routine in the health services research context. Nonetheless, our mapping of process evaluation components to outcomes reported in the trial results papers suggests that process was considered, even if they did not publish a separate process evaluation paper. This leads us to question the definition of process evaluation. Our perception of a process evaluation is 
Table 6 Summary of recommendations

\begin{tabular}{|c|c|}
\hline $\begin{array}{l}\text { Recommendations for process evaluation } \\
\text { design }\end{array}$ & $\begin{array}{l}\text { - Consider the identified potential values of process evaluation within pragmatic RCTs } \\
\text { and how these may be realised and articulated to stakeholders } \\
\text { - We encourage debate about the meaning of the label 'process evaluation' and how } \\
\text { it may be more consistently applied }\end{array}$ \\
\hline $\begin{array}{l}\text { Recommendations for process evaluation } \\
\text { conduct }\end{array}$ & $\begin{array}{l}\text { - Consider the identified barriers and facilitators and how to address these when } \\
\text { conducting process evaluations in health services settings }\end{array}$ \\
\hline $\begin{array}{l}\text { Recommendations for process evaluation } \\
\text { dissemination }\end{array}$ & $\begin{array}{l}\text { - Ensure process evaluation publications are included in the trial registry entry } \\
\text { - Ensure process evaluations are mentioned in journal articles reporting the parent trial, } \\
\text { and consider adding this item to relevant CONSORT checklists } \\
\text { - Ensure process evaluation publications name or refer to the parent trial in the title or abstract } \\
\text { - Publish strategies for conducting successful process evaluations and addressing challenges in } \\
\text { health services settings, such as to recruiting process evaluation participants and collecting data }\end{array}$ \\
\hline
\end{tabular}

that it is more substantial than measuring a single process outcome; however, when extensive process data are reported within trial results, the distinction between 'a process evaluation' and this suite of process data is less clear.

Further need for definitional clarity is demonstrated by the paucity and inconsistency of use of the label 'process evaluation' in the 17 separate studies. This echoes a finding of a previous systematic review [10], which reported only 32 of 124 'process evaluations' used the label-a similar proportion to the labelling in our studies.

The MRC guidance [4] states that there is no unified definition of process evaluation, and the theoretical scope laid out in process evaluation frameworks and guidance $[4,5,8,9]$ is very broad, encompassing many methods, areas of investigation, and scales of study. This wide variety of possible characteristics of process evaluation is likely to generate confusion and may explain the inconsistent use of the label. Furthermore, the MRC guidance [4] only discusses process evaluation of interventions; however, in common with other authors [5, 50-53], we identified the important role for process evaluation in evaluating trial processes, such as recruitment and patient experience of trial participation. We therefore believe simply repeating previous calls for clearer labelling [5] is insufficient and recommend further discussion about the meaning of the term 'process evaluation'.

\section{Barriers and facilitators}

We identified several barriers and facilitators to process evaluation researchers collecting optimal data, recruiting participants, and working within regulatory frameworks in the real-world health service contexts in which pragmatic RCTs operate. Several of these identified challenges and enablers are not addressed in the MRC guidance [4]; however, a previous systematic review [10] recommended monitoring and reporting process evaluation recruitment. We recommend researchers continue to share their experiences of challenges and successful strategies for conducting process evaluations in this context.

\section{Indexing and visibility}

Process evaluations often had poor visibility through not being mentioned in trial results papers, and/or not included in trial registries. Furthermore, time delay to publication, not naming trials in titles or abstracts, and not labelling or indexing as process evaluations were significant barriers to locating articles in citation searches. Reporting guidance for process evaluations is available $[4,5]$, emphasising the importance of linking outcome and process evaluation papers. Our findings demonstrate the importance of following these recommendations, specifically that outcome results journal articles should mention that a process evaluation was undertaken, and process evaluation journal articles should name or explicitly link to the trial in their title or abstract. We additionally recommend process evaluation articles are included in trial registries and that mention of any process evaluation undertaken could usefully be added to relevant CONSORT trial reporting checklists [54, 55]. We also highlight that some HTA monographs reported process evaluations alongside trial outcomes and integrated discussion of findings [23, 26, 34, 36, 42], and therefore demonstrate a useful reporting format.

\section{Strengths and limitations}

The key design strength of this review was using an index sample of pragmatic RCTs and then identifying any reported 'process evaluation' using an operational definition. This provided valuable information on process evaluation frequency and accessibility and highlighted the inconsistency of the use of the 'process evaluation' label. However, a limitation is that we could include only a sample of pragmatic RCTs. Limiting to trials published in MEDLINE Core Clinical Journals means findings are likely reflective of well-funded health services research trials but may not be representative of trials published elsewhere. We also only included RCTs described as 'pragmatic' in the title or abstract. As such labelling is not an essential reporting criterion for pragmatic RCTs [54], trials were not identified for inclusion if they only used the term 'pragmatic' elsewhere in the paper. 
Limiting index trial inclusion to publication in 2015 ensured a reasonable length of time for publication of process evaluation papers, and indeed, two process evaluations were published in 2019. However, this also means findings may not be representative of process evaluations being designed and conducted now. Our findings can therefore only highlight potential areas of uncertainty, difficulty, or opportunity, with alternative research approaches such as surveys or interviews needed to examine current practice. We also acknowledge as a limitation that we used the MRC process evaluation framework to identify and describe process evaluations, when most process evaluations in our sample (associated with trials published in 2015) would very likely have been designed prior to publication of the MRC guidance [4].

The search methods for identifying associated publications were comprehensive, with a good response rate from authors. We used a robust process for deciding which publications to categorise as process evaluations, and the team included highly experienced health service researchers with experience of designing and conducting process evaluations. We acknowledge others may disagree with our operational definition and categorisations; however, we highlight this ambiguity is itself an important finding.

Double data extraction was carried out on fields we considered to be subjective, increasing the reliability of findings. There are currently no agreed quality assessment standards for process evaluations [4], and therefore, we did not appraise the quality of included studies; however, doing so would add to and strengthen the findings.

\section{Conclusion}

This review provides valuable insight into the frequency and characteristics of process evaluations, within a sample of systematically identified index pragmatic RCTs published in a single year, and highlights challenges and enablers to their practical conduct in health services settings. Significantly, it suggests that the definition of process evaluation is inconsistent and that the meaning of the term requires clarification. Despite the wide range of identified values of process evaluations, this review highlights important problems with accessibility, which are likely barriers to fully realising this value. Often, process evaluations are invisible in pragmatic RCT reporting, and we therefore make several straightforward but significant reporting recommendations.

\section{Supplementary information}

Supplementary information accompanies this paper at https://doi.org/10. 1186/s13063-020-04762-9.

Additional file 1. MEDLINE (Ovid) search strategy.

Additional file 2. Trial descriptor data fields.

Additional file 3. PRISMA 2009 checklist. Completed PRISMA checklist.
Additional file 4. Included pragmatic RCTs. Details and references of the 31 index pragmatic RCTs.

Additional file 5. Items mapped to each process evaluation component.

Additional file 6. All extracted values of process evaluation.

\section{Abbreviations}

HTA: Health Technology Assessment (UK National Institute of Health Research funding programme); MRC: Medical Research Council; RCT: Randomised controlled trial

\section{Acknowledgements}

Thank you to all corresponding authors.

Thank you to Dr. Nina Fudge for reviewing draft manuscripts and to Paula

Funnell, faculty liaison librarian, for advising on the search strategy.

\section{Authors' contributions}

CF, supervised by ST and HP, designed the review and conducted the searches, data extraction, and analysis. GF and IS undertook double data extraction and checking. The authors read and approved the final manuscript.

\section{Funding}

CF was funded by a PhD studentship awarded by Queen Mary University of London. This report is independent research supported by the National Institute for Health Research. ST is supported by the National Institute for Health Research ARC North Thames. The views expressed in this publication are those of the authors and not necessarily those of the National Institute for Health Research, the NHS, or the Department of Health and Social Care.

\section{Availability of data and materials}

The datasets used and/or analysed during the current study are available from the corresponding author on reasonable request.

Ethics approval and consent to participate

Not applicable

Consent for publication

Not applicable

\section{Competing interests}

The authors declare they have no competing interests.

\section{Author details}

${ }^{1}$ Institute of Population Health Sciences, Barts and the London School of Medicine and Dentistry, Queen Mary University of London, 58 Turner Street, London E1 2AB, UK. 'Usher Institute, The University of Edinburgh, Doorway 3, Medical School, Teviot Place, Edinburgh EH8 9AG, UK. 'Institute of Psychiatry, Psychology and Neuroscience (IoPPN), Kings College London, 16 De

Crespigny Park, London SE5 8AF, UK. ${ }^{4}$ Emergency Department, Royal London Hospital, Barts Health NHS Trust, Whitechapel, London E1 1FR, UK.

Received: 5 May 2020 Accepted: 22 September 2020

Published online: 09 November 2020

\section{References}

1. Barratt H, Campbell M, Moore L, Zwarenstein M, Bower P. Randomised controlled trials of complex interventions and large-scale transformation of services. Health Serv Deliv Res. 2016;4(16):19-36.

2. Moore GF, Audrey S, Barker M, Bond L, Bonell C, Hardeman W, et al. Process evaluation of complex interventions: medical research council guidance. $\mathrm{Br}$ Med J. 2015;350:h1258.

3. Raine R, Fitzpatrick R, Barratt H, Bevan G, Black N, Boaden R, et al. Challenges, solutions and future directions in the evaluation of service innovations in health care and public health. Health Serv Deliv Res. 2016; 4(16).

4. Moore G, Audrey S, Barker M, Bond L, Bonell C, Hardeman W, et al. Process evaluation of complex interventions: UK Medical Research Council (MRC) guidance. London: MRC Population Health Science Network; 2014. 
5. Grant A, Treweek S, Dreischulte T, Foy R. Process evaluations for clusterrandomised trials of complex interventions: a proposed framework for design and reporting. Trials. 2013;14(1):15.

6. Loudon $K$, Treweek S, Sullivan F, Donnan $P$, Thorpe KE, Zwarenstein M. The PRECIS-2 tool: designing trials that are fit for purpose. Br Med J. 2015;350: h2147.

7. Masterson-Algar P, Burton CR, Rycroft-Malone J. The generation of consensus guidelines for carrying out process evaluations in rehabilitation research. BMC Med Res Methodol. 2018;18(1):180.

8. Steckler $A B$, Linnan $L$. Process evaluation for public health interventions and research. San Francisco: Jossey-Bass; 2002.

9. Baranowski T, Stables G. Process evaluations of the 5-a-day projects. Health Educ Behav. 2000;27(2):157-66.

10. Masterson-Algar $P$, Burton CR, Rycroft-Malone J. Process evaluations in neurological rehabilitation: a mixed-evidence systematic review and recommendations for future research. BMJ Open. 2016;6(11):e013002.

11. Yeary $K H$, Klos LA, Linnan $L$. The examination of process evaluation use in church-based health interventions: a systematic review. Health Promot Pract. 2012;13(4):524-34.

12. Wierenga $D$, Engbers LH, Van Empelen P, Duijts $S$, Hildebrandt VH, Van Mechelen W. What is actually measured in process evaluations for worksite health promotion programs: a systematic review. BMC Public Health. 2013; 13(1):1190.

13. Robbins SCC, Ward K, Skinner SR. School-based vaccination: a systematic review of process evaluations. Vaccine. 2011;29(52):9588-99.

14. Murta SG, Sanderson K, Oldenburg B. Process evaluation in occupational stress management programs: a systematic review. Am J Health Promot. 2007;21(4):248.

15. Munodawafa M. Process evaluations of task sharing interventions for perinatal depression in low and middle income countries (LMIC): a systematic review and qualitative meta-synthesis. BMC Health Serv Res. 2018;18(1):205

16. Nicholls SG, Carroll K, Zwarenstein M, Brehaut JC, Weijer C, Hey SP, et al. The ethical challenges raised in the design and conduct of pragmatic trials: an interview study with key stakeholders. Trials. 2019;20(1):765.

17. O'Cathain A, Thomas KJ, Drabble SJ, Rudolph A, Goode J, Hewison J. Maximising the value of combining qualitative research and randomised controlled trials in health research: the QUAlitative Research in Trials (QUART) study-a mixed methods study. Health Technol Assess. 2014;18(38).

18. Moher D, Liberati A, Tetzlaff J, Altman DG. Preferred reporting items for systematic reviews and meta-analyses: the PRISMA statement. Ann Intern Med. 2009;151(4):264-9.

19. Hill AM, McPhail SM, Waldron N, Etherton-Beer C, Ingram K, Flicker L, et al. Fall rates in hospital rehabilitation units after individualised patient and staff education programmes: a pragmatic, stepped-wedge, cluster-randomised controlled trial. Lancet. 2015;385(9987):2592-9.

20. Rangan A, Handoll H, Brealey S, Jefferson L, Keding A, Martin BC, et al. Surgical vs nonsurgical treatment of adults with displaced fractures of the proximal humerus: the PROFHER randomized clinical trial. JAMA. 2015; 313(10):1037-47

21. Lamb SE, Williamson EM, Heine PJ, Adams J, Dosanjh S, Dritsaki M, et al. Exercises to improve function of the rheumatoid hand (SARAH): a randomised controlled trial. Lancet. 2015;385(9966):421-9.

22. Ball J, Løchen M-L, Carrington MJ, Wiley JF, Stewart S. Mild cognitive impairment impacts health outcomes of patients with atrial fibrillation undergoing a disease management intervention. Open Heart. 2018;5(1): e000755.

23. Clark TJ, Middleton LJ, Am Cooper N, Diwakar L, Denny E, Smith P, et al. A randomised controlled trial of Outpatient versus inpatient Polyp Treatment (OPT) for abnormal uterine bleeding. Health Technol Assess. 2015;19(61).

24. Grubbs KM, Fortney JC, Pyne JM, Hudson T, Moore WM, Custer P, et al. Predictors of initiation and engagement of cognitive processing therapy among veterans with PTSD enrolled in collaborative care: predictors of CPT use in TOP. J Trauma Stress. 2015;28(6):580-4.

25. Handoll H, Brealey S, Jefferson L, Keding A, Brooksbank A, Johnstone A, et al. Defining the fracture population in a pragmatic multicentre randomised controlled trial. Bone Joint Res. 2016:5(10):481-9.

26. Handoll H, Brealey S, Rangan A, Keding A, Corbacho B, Jefferson L, et al. The ProFHER (PROximal Fracture of the Humerus: Evaluation by Randomisation) trial - a pragmatic multicentre randomised controlled trial evaluating the clinical effectiveness and cost-effectiveness of surgical compared with nonsurgical treatment for proximal fracture of the humerus in adults. Health Technol Assess. 2015;19(24).

27. Handoll H, Goodchild L, Brealey S, Hanchard N, Jefferson L, Keding A, et al. Developing, delivering and documenting rehabilitation in a multi-centre randomised controlled surgical trial. Bone Joint Res. 2014;3(12):335-40.

28. Hall AM, Copsey B, Williams M, Srikesavan C, Lamb SE. Mediating effect of changes in hand impairments on hand function in patients with rheumatoid arthritis: exploring the mechanisms of an effective exercise program. Arthritis Care Res. 2017;69(7):982-8.

29. Hill A-M, Waldron N, Francis-Coad J, Haines T, Etherton-Beer C. 'It promoted a positive culture around falls prevention': staff response to a patient education programme-a qualitative evaluation. BMJ Open. 2016;6(12): e013414.

30. Hill A-M, Francis-Coad J, Haines TP, Waldron N, Etherton-Beer C. 'My independent streak may get in the way': how older adults respond to falls prevention education in hospital. BMJ Open. 2016;6(7):e012363.

31. Hill A-M, MCPhail SM, Francis-Coad J, Waldron N, Etherton-Beer C. Educators' perspectives about how older hospital patients can engage in a falls prevention education programme: a qualitative process evaluation. BMJ Open. 2015;5(12):e009780.

32. Keding A, Handoll H, Brealey S, Jefferson L, Hewitt C, Corbacho B, et al. The impact of surgeon and patient treatment preferences in an orthopaedic trauma surgery trial. Trials. 2019;20(1):570.

33. Knowles SE, Lovell K, Bower P, Gilbody S, Littlewood E, Lester H. Patient experience of computerised therapy for depression in primary care. BM Open. 2015;5(11):e008581.

34. Littlewood E, Duarte A, Hewitt C, Knowles S, Palmer S, Walker S, et al. A randomised controlled trial of computerised cognitive behaviour therapy for the treatment of depression in primary care: the Randomised Evaluation of the Effectiveness and Acceptability of Computerised Therapy (REEACT) trial. Health Technol Assess. 2015;19(101).

35. Nichols VP, Williamson E, Toye F, Lamb SE. A longitudinal, qualitative study exploring sustained adherence to a hand exercise programme for rheumatoid arthritis evaluated in the SARAH trial. Disabil Rehabil. 2017; 39(18):1856-63.

36. Williams MA, Williamson EM, Heine PJ, Nichols V, Glover MJ, Dritsaki M, et al. Strengthening and Stretching for Rheumatoid Arthritis of the Hand (SARA H). A randomised controlled trial and economic evaluation. Health Technol Assess. 2015;19(19).

37. Novak DJ, Bai Y, Cooke RK, Marques MB, Fontaine MJ, Gottschall JL, et al. Making thawed universal donor plasma available rapidly for massively bleeding trauma patients: experience from the Pragmatic, Randomized Optimal Platelets and Plasma Ratios (PROPPR) trial. Transfusion. 2015;55(6):1331-9.

38. Sands G, Kelly D, Fletcher-Smith J, Birt L, Sackley C. An occupational therapy intervention for residents with stroke living in care homes in the United Kingdom: a content analysis of occupational therapy records from the OTCH trial. Br J Occup Ther. 2015;78(7):422-30.

39. Saville AW, Gurfinkel D, Sevick C, Beaty B, Dickinson LM, Kempe A. Provider preferences and experiences with a countywide centralized collaborative reminder/recall for childhood immunizations. Acad Pediatr. 2016;16(1):50-6.

40. Tjia J, Kutner JS, Ritchie CS, Blatchford PJ, Bennett Kendrick RE, Prince-Paul $M$, et al. Perceptions of statin discontinuation among patients with lifelimiting illness. J Palliat Med. 2017;20(10):1098-103.

41. Vennik J, Williamson I, Eyles C, Everitt H, Moore M. Nasal balloon autoinflation for glue ear in primary care: a qualitative interview study. $\mathrm{Br}$ J Gen Pract. 2019;69(678):e24-32

42. Williamson I, Vennik J, Harnden A, Voysey M, Perera R, Breen M, et al. An open randomised study of autoinflation in 4- to 11-year-old school children with otitis media with effusion in primary care. Health Technol Assess. 2015;19(72).

43. Moseley AM, Beckenkamp PR, Haas M, Herbert RD, Lin CW, Team E. Rehabilitation after immobilization for ankle fracture: the EXACT randomized clinical trial. JAMA. 2015;314(13):1376-85.

44. Fortney JC, Pyne JM, Kimbrell TA, Hudson TJ, Robinson DE, Schneider R, et al. Telemedicine-based collaborative care for posttraumatic stress disorder: a randomized clinical trial. JAMA Psychiatry. 2015;72(1):58-67.

45. Holcomb JB, Tilley BC, Baraniuk S, Fox EE, Wade CE, Podbielski JM, et al. Transfusion of plasma, platelets, and red blood cells in a 1:1:1 vs a 1:1:2 ratio and mortality in patients with severe trauma: the PROPPR randomized clinical trial. JAMA. 2015;313(5):471-82. 
46. Honkoop PJ, Loijmans RJ, Termeer EH, Snoeck-Stroband JB, van den Hout WB, Bakker MJ, et al. Symptom- and fraction of exhaled nitric oxide-driven strategies for asthma control: a cluster-randomized trial in primary care. J Allergy Clin Immunol. 2015;135(3):682-8.e11.

47. Gilbody S, Littlewood E, Hewitt C, Brierley G, Tharmanathan P, Araya R, et al. Computerised cognitive behaviour therapy (CCBT) as treatment for depression in primary care (REEACT trial): large scale pragmatic randomised controlled trial. BMJ. 2015;351:h5627.

48. Sackley $\mathrm{CM}$, Walker MF, Burton $\mathrm{CR}$, Watkins $\mathrm{CL}$, Mant J, Roalfe $\mathrm{AK}$, et al. An occupational therapy intervention for residents with stroke-related disabilities in UK Care Homes (OTCH): cluster randomised controlled trial with economic evaluation. Health Technol Assess. 2016;20(15).

49. O'Cathain A, Thomas K, Drabble S, Rudolph A, Hewison J. What can qualitative research do for randomised controlled trials? A systematic mapping review. BMJ Open. 2013;3(6):e002889.

50. Bakker FC, Persoon A, Schoon Y, Olde Rikkert MGM. Uniform presentation of process evaluation results facilitates the evaluation of complex interventions: development of a graph: presenting process evaluation's results. J Eval Clin Pract. 2015;21(1):97-102.

51. Morgan-Trimmer S, Wood F. Ethnographic methods for process evaluations of complex health behaviour interventions. Trials. 2016;17(1):232.

52. Wells M, Williams B, Treweek S, Coyle J, Taylor J. Intervention description is not enough: evidence from an in-depth multiple case study on the untold role and impact of context in randomised controlled trials of seven complex interventions. Trials. 2012;13(1):95.

53. Oakley A. Evaluating processes a case study of a randomized controlled tria of sex education. Evaluation. 2004;10(4):440-62.

54. Zwarenstein M, Treweek S, Gagnier JJ, Altman DG, Tunis S, Haynes B, et al. Improving the reporting of pragmatic trials: an extension of the CONSORT statement. BMJ. 2008;337:a2390.

55. Boutron I, Altman DG, Moher D, Schulz KF, Ravaud P. CONSORT statement for randomized trials of nonpharmacologic treatments: a 2017 update and a CONSORT extension for nonpharmacologic trial abstracts. Ann Intern Med. 2017;167(1):40-7.

\section{Publisher's Note}

Springer Nature remains neutral with regard to jurisdictional claims in published maps and institutional affiliations.

Ready to submit your research? Choose BMC and benefit from:

- fast, convenient online submission

- thorough peer review by experienced researchers in your field

- rapid publication on acceptance

- support for research data, including large and complex data types

- gold Open Access which fosters wider collaboration and increased citations

- maximum visibility for your research: over $100 \mathrm{M}$ website views per year

At $\mathrm{BMC}$, research is always in progress.

Learn more biomedcentral.com/submissions 